\title{
Qualitative modelling of functional relationships in marine benthic communities
}

\author{
Alexandridis Nikolaos ${ }^{1,{ }^{*}}$, Dambacher Jeffrey M. ${ }^{2}$, Jean Fred ${ }^{3}$, Desroy Nicolas ${ }^{4}$, Bacher Cedric ${ }^{1}$ \\ 1 IFREMER, Centre de Bretagne, DYNECO-LEBCO, CS 10070, 29280 Plouzané, France \\ ${ }^{2}$ CSIRO, GPO Box 1538, Hobart, Tasmania 7001, Australia \\ ${ }^{3}$ Université de Brest, UBO, CNRS, IRD, Institut Universitaire Européen de la Mer, LEMAR, 29280 \\ Plouzané, France \\ ${ }^{4}$ IFREMER, Laboratoire Environnement et Ressources de Bretagne Nord, BP 70134, 35801 Dinard, \\ France \\ * Corresponding author : Nikolaos Alexandridis, email address : nikolaos.alexandridis@ifremer.fr
}

\begin{abstract}
:
In order to better understand and predict the dynamics of benthic macroinvertebrate communities, we need to first define the functional components of benthic biodiversity and then provide a mechanistic description of how they interact with their abiotic environment, their basic resources and each other. These interactions should be largely controlled by readily available biological traits, making trait-based modelling an ideal framework for the synthesis of relevant hypotheses from ecological theory and expert knowledge. With the help of benthic species traits, we derived a set of first principles regarding the role of organisms in processes of environmental filtering, consumption of algae/detritus, predation, use of space, biogenic habitat modification and trade-offs in the utilization and allocation of resources. These principles were incorporated into qualitative models in the form of functional relationships linking groups of benthic organisms in the Rance estuary (Brittany, France). The general stability of these models illustrates their potential to persist in time and to constitute a plausible representation of the natural world. Their structure provides insight into the role of various community assembly mechanisms and the direction that the system might take in response to perturbations. The results are expected to inform the development of quantitative models reproducing the spatial and temporal dynamics of marine benthic biodiversity in the Rance estuary.
\end{abstract}

\section{Highlights}

We derived first principles on the role of benthic organisms in community assembly. These principles dictated functional relationships among groups of benthic species. $\rightarrow$ Groups and functional relationships comprised qualitative models of benthic systems. - Stability analysis supported the models' potential to represent benthic communities. Model structure offered insight into the role of some community assembly mechanisms.

Keywords: Benthic macroinvertebrates, Biological traits, Biotic interactions, Community assembly, Functional groups, Qualitative modelling 
39 Introduction

40 Reliable prediction of biodiversity responses to environmental change remains a

41 key challenge of ecological research (Sutherland et al., 2013). Because it involves

42 combinations of species and environmental gradients that have not been observed

43 yet, it requires a mechanistic understanding of the processes that shape biological

44 communities (Kearney and Porter, 2009). Ecological theory has generated many

45 hypotheses about the maintenance of species diversity (Chesson, 2000). However,

46 empirical investigation of these hypotheses has been mostly performed by studies of

47 relatively small spatial and temporal scales (Cardinale et al., 2012). This has limited

48 the potential of their findings to be extrapolated to larger scales and has added

49 uncertainty to projected trends of biodiversity (Pereira et al., 2010). 
In ecological systems where observation and experimentation fall short of fully

51 revealing the drivers of biodiversity, the analysis of mechanistic models has been suggested as an alternative way of identifying the most likely community assembly mechanisms (Amarasekare, 2003). Since the role of organisms in the functioning of ecosystems is defined by their traits, the development of trait-based modelling approaches has been suggested as a fruitful avenue for models of ecological systems (Ings et al., 2009). Limited understanding of specific mechanisms should not exclude them from the modelling procedure (Queirós et al., 2015). Instead, awareness about the assumptions that are made at each step should allow models to test alternative hypotheses, elucidate domains of uncertainty and identify critical areas for research.

The development of mechanistic models of biodiversity can be considered to be subject to two main conditions. First, the functional components of biodiversity need to be defined through rigorous and testable procedures (Petchey and Gaston, 2006). Next, a mechanistic description of the way these components interact with their environment and among themselves is necessary. These issues have traditionally been addressed in the context of food web modelling. Organisms are typically separated into groups according to their food sources, and interactions among them are assumed to represent their trophic behaviour (Yodzis and Innes, 1992). In lack of empirical information to help formulate these models, various methods have been developed for the construction of food webs, based on principles of community (e.g., Cohen and Newman, 1985; Williams and Martinez, 2000; Cattin et al., 2004) or ecosystem ecology (e.g., Fath, 2004; Morris et al., 2005; Halnes et al., 2007). Still, a disproportionate focus on trophic interactions has restricted the scope of most modelling efforts (but see Kéfi et al. (2012)). 
Predicting biodiversity patterns is particularly challenging for communities of marine benthic macroinvertebrates (Constable, 1999). The study of these systems has long suffered from a lack of empirical information (Solan et al., 2003), while nontrophic interactions often play a central role. Many of these organisms can alter the physical or chemical properties of their environment in ways that significantly impact other members of their communities (Meadows et al., 2012). These effects appear to be non-linear and form intricate feedback cycles (Herman et al., 1999), while they can greatly vary among different life stages (Pineda et al., 2009). Along with the prevalence of omnivory and facultative feeding modes, this has reduced the pertinence of classic trophic groupings of benthic macrofauna (Snelgrove and Butman, 1994). Moreover, theoretically derived allometries that have facilitated the quantification of trophic interactions appear to be less efficient for their non-trophic counterparts (Berlow et al., 2009; Petchey et al., 2008), in support of a more mechanistic representation of the latter.

Quite independent of mechanistic modelling, an increased interest in the functioning of marine benthic communities has led to the compilation of large data bases of species traits. At the same time, theoretical and expert knowledge about potential trait associations is being continuously generated. Particularly lacking is a systematic procedure for the assignment of functional groupings and inter-group relationships on the basis of such readily available information. Recent work in the terrestrial environment led to the development of a trait-based method for the construction of functional groups for models of plant diversity (Boulangeat et al., 2012). The conceptual and methodological framework was provided by the emergent group hypothesis, which assumes functional equivalence within and functional divergence among emergent groups of species (Hérault, 2007). The adaptation of 
100 this framework to the benthic macroinvertebrate communities of the Rance estuary

101 (Brittany, France) can provide the functional components for a mechanistic 102 representation of the system (Alexandridis et al., 2017). Here we implement these

103 components in a demonstration of a systematic procedure for the assignment of

104 functional relationships between them. In a first conception of the system, we are

105 restricted to the qualitative nature of the relationships.

106 The objective of our study is to use mechanistic models of benthic macrofauna,

107 in order to assess the role of different processes in shaping biodiversity patterns in 108 the Rance estuary. To this end, we represented benthic macroinvertebrate 109 communities through signed-directed graph (or signed digraph) models. The 110 previously defined groups of species comprised the functional components of the 111 system and were assigned to sub-systems based on rules of environmental filtering. 112 In each of these sub-systems, groups were linked by functional relationships that 113 were largely derived from ecological theory and expert knowledge regarding general 114 community assembly mechanisms. This procedure was dictated by each group's 115 assigned trait values and representative species. The stability analysis of the signed 116 digraphs demonstrated the potential of the respective systems to persist in time and, 117 therefore, to constitute a plausible representation of the natural world. The structure 118 of the models gave some insight into the role of different community assembly 119 mechanisms, as well as the direction of the system's response to potential 120 perturbations. This work serves as a first step toward quantitative mechanistic models 121 that will be able to reproduce the spatial and temporal dynamics of benthic 122 biodiversity in the Rance estuary (Alexandridis, 2017). 
Methods

$126 \quad 2.1$

127 Study site

128 The Rance estuary (Brittany, France) is situated in the southern part of the

129 English Channel (Fig. 1). The site is characterized by the presence of a tidal power

130 plant at its mouth. The operating constraints of the installation have reduced the tidal

131 range in the estuary compared to the open sea. The intertidal zone has shifted from

$13270 \%$ of the total surface of the estuary before the construction of the power plant, to

$13350 \%$ after. Maximum water depth is $17 \mathrm{~m}$ at low tide, but the main part of the basin is

$134 \quad 5-6 \mathrm{~m}$ deep. The sluice and turbine currents from the power plant have eroded parts

135 of the riverbed. Sandbanks closest to the dam have shifted and the bed is 136 predominantly covered with gravel or pebbles (Retière, 1994). At the same time, long 137 periods of slack water have promoted the deposition of fine particles in coves and 138 bays (Bonnot-Courtois and Lafond, 1991). From downstream to upstream of the 139 estuary, pebbles and coarse sands are replaced by medium and fine sands, muddy 140 sands and finally muds upstream of Port-St-Hubert. A similar sequence is observable 141 from the central channel of the estuary to its banks.

142 Sediment samples were collected from 113 stations on the bed of the Rance 143 estuary in April 1995, prior to the spring recruitment (Fig. 1). The sampled stations 144 are expected to represent the variability of benthic communities in the system. A total 145 of 240 macroinvertebrate (i.e., retained by a $1 \mathrm{~mm}$ sieve) species or higher taxonomic 146 groups belonging to 9 phyla were identified in the samples and their abundances in 147 each station were measured (Desroy, 1998). 


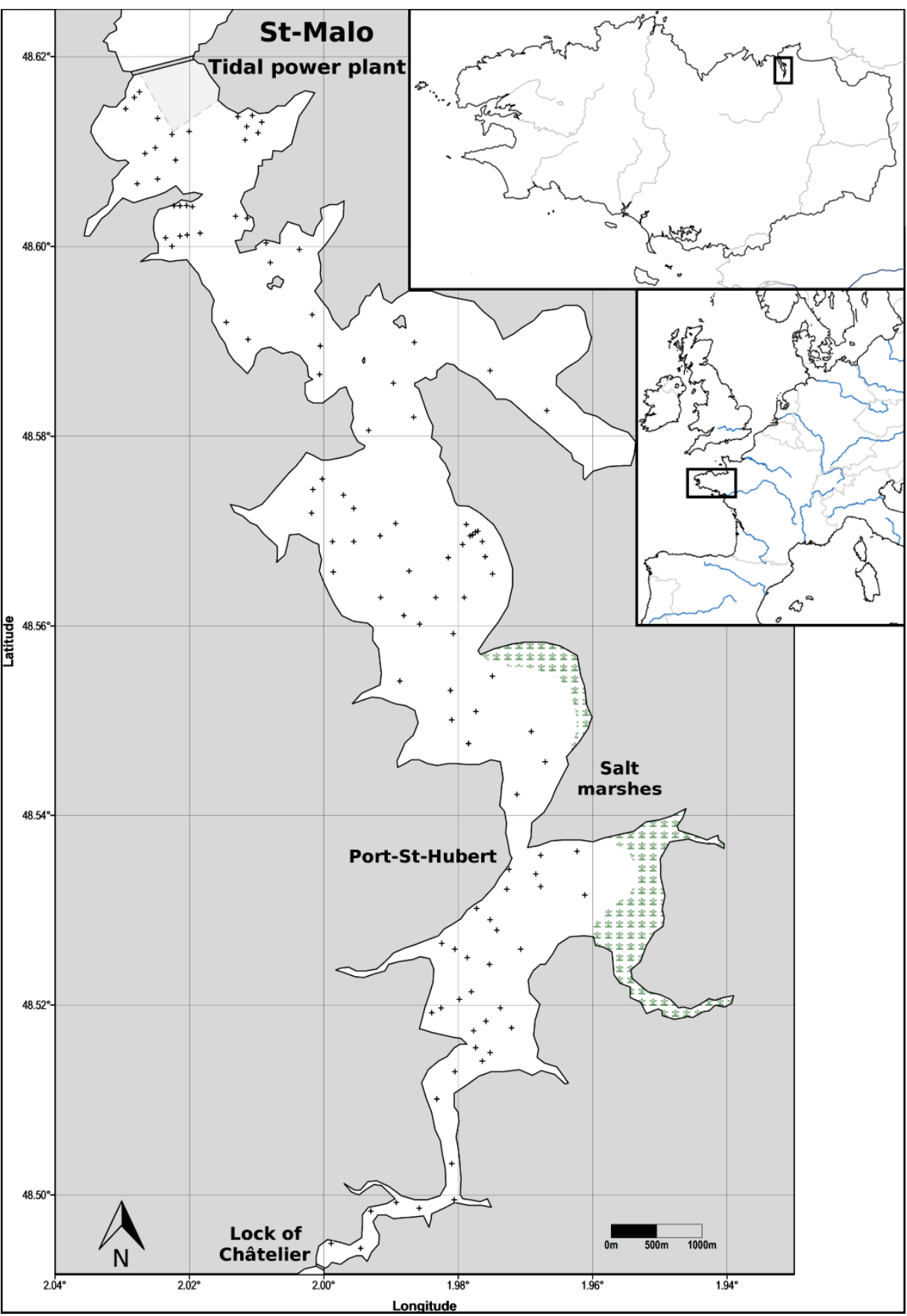

150 Fig. 1. Map of the study site. The Rance estuary is situated on the northern coast of

151 Brittany, France. Crosses indicate the location of the 113 stations that were sampled

152 in the spring of 1995 . The tidal power plant is located at the mouth of the estuary,

153 south of the city of St-Malo

156 Functional groups 
157 For the representation of the primary functional components of benthic 158 macroinvertebrate communities in the Rance estuary, we employed 20 functional 159 groups, previously built on the basis of biological trait information for the 240 species 160 of the system in 1995 (Alexandridis et al., 2017). The collected abundance data set 161 allowed each of the groups to be assigned with a representative species along with a 162 value for each of the 14 biological traits (Table 1 ). The traits are expected to describe 163 the role of benthic algae/detritus feeders and predators/scavengers in 7 important 164 community assembly mechanisms (Table 2). The list of mechanisms was mostly 165 adopted from the framework developed by Boulangeat et al. (2012) for dynamic 166 models of terrestrial vegetation. A few adjustments were made to the original 167 framework, in order to adapt it to marine benthic systems (Alexandridis et al., 2017). 168 
169 Table 1. Functional groups with their assigned representative species and biological trait values (Alexandridis et al., 2017). For

170 details about the biological traits, see Table 2. Group names starting with ' $\mathrm{H}$ ' correspond to groups of algae/detritus feeders and 171 those starting with 'C' correspond to groups of predators/scavengers

\begin{tabular}{|c|c|c|c|c|c|c|c|c|c|c|c|c|c|c|c|}
\hline Groups & Representative species & T1. temperature & T2. development & T3. dispersal & T4. fecundity & T5. tide/salinity & T6. substrate & T7. size $(\mathrm{cm})$ & T8. area & T9. position & T10. mobility & T11. growth rate & T12. lifespan (yr) & T13. epibiosis & T14. engineering \\
\hline $\mathrm{H} 1$ & Morchellium argus & eurythermal & brooded & short & low & stenohaline & rock & 3.3 & 0.1 & epifauna & sessile & 2.6 & 1.7 & epibiont & neutral \\
\hline H2 & Lepidochitona cinerea & stenothermal & planktonic & short & high & stenohaline & rock & 10.8 & 4.1 & epifauna & mobile & 0.9 & 11.6 & epibiont & neutral \\
\hline $\mathrm{H} 3$ & Balanus crenatus & eurythermal & planktonic & long & high & euryhaline & rock & 2.0 & 0.8 & epifauna & sessile & 2.5 & 2.0 & epibiont & neutral \\
\hline $\mathrm{H} 4$ & Crepidula fornicata & stenothermal & planktonic & long & high & stenohaline & rock & 7.6 & 0.0 & epifauna & sessile & 1.9 & 11.2 & basibiont & neutral \\
\hline H5 & Oligochaeta & stenothermal & laid & short & low & emersed & muddy sand & 4.5 & 5.0 & infauna & mobile & 3.4 & 2.0 & neutral & destabilizer \\
\hline $\mathrm{H} 6$ & Thyasira flexuosa & eurythermal & planktonic & short & low & stenohaline & mud & 3.6 & 0.8 & infauna & mobile & 1.0 & 10.0 & neutral & stabilizer \\
\hline $\mathrm{H} 7$ & Melinna palmata & stenothermal & brooded & short & low & stenohaline & mud & 7.5 & 0.3 & interface & sessile & 2.6 & 3.6 & neutral & stabilizer \\
\hline $\mathrm{H} 8$ & Notomastus latericeus & stenothermal & brooded & short & low & stenohaline & muddy sand & 6.0 & 2.9 & interface & mobile & 2.6 & 1.9 & neutral & destabilizer \\
\hline H9 & Hediste diversicolor & eurythermal & laid & short & high & emersed & muddy sand & 12.8 & 0.2 & interface & mobile & 2.1 & 3.4 & neutral & destabilizer \\
\hline $\mathrm{H} 10$ & Malacoceros fuliginosus & eurythermal & planktonic & long & high & euryhaline & mud & 8.5 & 1.9 & interface & mobile & 2.5 & 2.7 & neutral & destabilizer \\
\hline $\mathrm{H} 11$ & Galathowenia oculata & eurythermal & planktonic & long & high & euryhaline & mud & 11.1 & 0.0 & interface & sessile & 2.7 & 4.4 & neutral & stabilizer \\
\hline $\mathrm{H} 12$ & Glycymeris glycymeris & stenothermal & planktonic & short & high & stenohaline & muddy gravel & 8.0 & 1.4 & infauna & mobile & 0.8 & 15.0 & neutral & stabilizer \\
\hline $\mathrm{H} 13$ & Anapagurus hyndmanni & stenothermal & planktonic & long & high & stenohaline & gravel & 10.0 & 0.1 & epifauna & mobile & 0.6 & 10.0 & neutral & neutral \\
\hline $\mathrm{H} 14$ & Cerastoderma edule & stenothermal & planktonic & long & high & emersed & muddy sand & 8.6 & 0.5 & interface & mobile & 0.7 & 8.9 & neutral & stabilizer \\
\hline C1 & Sphaerosyllis bulbosa & stenothermal & brooded & short & low & stenohaline & gravel & 1.3 & 0.5 & epifauna & mobile & 4.7 & 1.9 & neutral & neutral \\
\hline $\mathrm{C} 2$ & Marphysa bellii & stenothermal & planktonic & short & high & stenohaline & muddy sand & 23.3 & 0.3 & interface & mobile & 1.1 & 4.7 & neutral & neutral \\
\hline C3 & Nephtys hombergii & stenothermal & planktonic & long & high & stenohaline & gravel & 10.5 & 0.3 & interface & mobile & 2.2 & 7.3 & neutral & neutral \\
\hline C4 & Myrianida edwardsi & stenothermal & planktonic & long & low & stenohaline & mud & 1.4 & 3.1 & interface & mobile & 5.8 & 1.9 & neutral & neutral \\
\hline C5 & Urticina felina & eurythermal & planktonic & short & high & euryhaline & rock & 16.7 & 10.3 & epifauna & sessile & 1.1 & 14.0 & epibiont & neutral \\
\hline C6 & Syllis cornuta & stenothermal & planktonic & long & low & stenohaline & rock & 7.4 & 5.2 & epifauna & mobile & 2.3 & 2.3 & epibiont & neutral \\
\hline
\end{tabular}


175 organisms' role in them, potential trait values and comments about their assignment

176 to the system's species, which formed the basis for the construction of the 20

\section{7 functional groups (Alexandridis et al., 2017)}

\begin{tabular}{llll}
\hline Mechanisms & Biological traits & Trait values & Comments \\
\hline $\begin{array}{l}\text { Resistance to } \\
\text { perturbation }\end{array}$ & $\begin{array}{l}\text { T1. low temperature } \\
\text { tolerance }\end{array}$ & eurythermal/stenothermal & $\begin{array}{l}\text { Species that can tolerate continued exposure to single-digit } \\
\text { temperatures (eurythermal) were distinguished from those that } \\
\text { cannot (stenothermal). }\end{array}$ \\
& $\begin{array}{l}\text { T2. early development } \\
\text { mode }\end{array}$ & planktonic/laid/brooded & $\begin{array}{l}\text { Trait values should define a gradient of increasing ability to } \\
\text { cope with perturbations during the early life stages, due to } \\
\text { increasing investment in early offspring survival. }\end{array}$
\end{tabular}

\begin{tabular}{llll}
\hline & $\begin{array}{l}\text { T3. larval dispersal } \\
\text { distance }\end{array}$ & short/long & $\begin{array}{l}\text { Species were separated in two groups based on their } \\
\text { maximum observed dispersal distance, with a distance of } \\
10 \mathrm{~km} \text { used as the breaking point. }\end{array}$ \\
potential & $\begin{array}{l}\text { T4. maximum } \\
\text { fecundity }\end{array}$ & low/high & $\begin{array}{l}\text { Species were separated in two groups, with the number } \\
1000 \text { eggs produced by a female of each species per yea }\end{array}$
\end{tabular}
used as the breaking point.

\begin{tabular}{|c|c|c|c|}
\hline \multirow{2}{*}{$\begin{array}{l}\text { Environmental } \\
\text { filtering }\end{array}$} & $\begin{array}{l}\text { T5. tidal emersion/ } \\
\text { low salinity tolerance }\end{array}$ & $\begin{array}{l}\text { emersed/euryhaline/ } \\
\text { stenohaline }\end{array}$ & $\begin{array}{l}\text { Soft bottom species that can tolerate long tidal exposure } \\
\text { should be able to tolerate low salinity (emersed). Immersed } \\
\text { species either can tolerate salinities that differ greatly from } \\
\text { those of the open sea (euryhaline) or cannot (stenohaline). }\end{array}$ \\
\hline & $\begin{array}{l}\text { T6. preferred } \\
\text { substrate type }\end{array}$ & $\begin{array}{l}\mathrm{mud} / \mathrm{muddy} \text { sand// } \\
\text { sand/muddy gravel/ } \\
\text { gravel/rock }\end{array}$ & $\begin{array}{l}\text { The assignment of one value to each species represented its } \\
\text { greatest substrate affinity, but was often too restrictive. }\end{array}$ \\
\hline \multirow{2}{*}{$\begin{array}{l}\text { Competitive } \\
\text { effect }\end{array}$} & T7. maximum size & $\begin{array}{l}1 \mathrm{~cm} / 2 \mathrm{~cm} / 10 \mathrm{~cm} / 20 \mathrm{~cm} / \\
40 \mathrm{~cm}\end{array}$ & $\begin{array}{l}\text { Trait values should define a gradient of increasing area that } \\
\text { can be searched for food or distance from the substrate, which } \\
\text { should enhance food availability (McLean and Lasker, 2013). }\end{array}$ \\
\hline & $\begin{array}{l}\text { T8. minimum space } \\
\text { requirement }\end{array}$ & $\begin{array}{l}0.003 / 0.1 / 49.5 \\
\text { (min./median/max.) } \\
\text { Values are not absolute, } \\
\text { but rather relative levels. }\end{array}$ & $\begin{array}{l}\text { Species with the lowest trait value should compete best for } \\
\text { space (Tilman, 1980). Trait values were derived from data on } \\
\text { body mass (Robinson et al., 2010) and use of an exponent of } \\
3 / 4 \text { from the metabolic theory of ecology (Jetz et al., 2004). }\end{array}$ \\
\hline \multirow{2}{*}{$\begin{array}{l}\text { Response to } \\
\text { competition }\end{array}$} & $\begin{array}{l}\text { T9. preferred } \\
\text { substrate position }\end{array}$ & infauna/interface/epifauna & $\begin{array}{l}\text { Living deep in the sediment (infauna), at its upper layer } \\
\text { (interface) or on its surface (epifauna) should allow species co- } \\
\text { existence in spite of established competitive hierarchies. }\end{array}$ \\
\hline & T10. adult mobility & mobile/sessile & $\begin{array}{l}\text { Differences in the ability of species to move should lead to } \\
\text { resource partitioning and avoidance of competition. }\end{array}$ \\
\hline \multirow{2}{*}{$\begin{array}{l}\text { Population } \\
\text { dynamics }\end{array}$} & $\begin{array}{l}\text { T11. population } \\
\text { growth rate }\end{array}$ & $\begin{array}{l}0.27 / 2.14 / 6.95 \\
\text { (min./median/max.) } \\
\text { Values are not absolute, } \\
\text { but rather relative levels. }\end{array}$ & $\begin{array}{l}\text { Trait values were derived from data on body mass (Robinson } \\
\text { et al., 2010) and use of an exponent of }-1 / 4 \text { from the metabolic } \\
\text { theory of ecology (Savage et al., 2004). }\end{array}$ \\
\hline & $\begin{array}{l}\text { T12. maximum } \\
\text { lifespan }\end{array}$ & $1 \mathrm{yr} / 2 \mathrm{yr} / 10 \mathrm{yr} / 20 \mathrm{yr}$ & $\begin{array}{l}\text { Different trait values should reflect differentiations in species } \\
\text { population dynamics. }\end{array}$ \\
\hline
\end{tabular}


T13. role in epibiosis basibiont/epibiont/neutral

Biogenic

habitat

modification

T14. role in sediment engineering
Species that can grow on other organisms (epibiont) were distinguished from those that also provide biotic substrate (basibiont). Neutral species do not participate in epibiosis.

Sediment destabilizing species should inhibit sessile, tube building species (stabilizers) and vice versa (Posey, 1987). Neutral species do not participate in sediment engineering.
178

179

$180 \quad 2.3$

181 Signed digraphs

182 The structure of the system was represented by signed digraphs (networks of

183 interactions that portray the interactions' direction and sign but not their strength)

184 (Levins, 1998). The functional groups and the basic resources of food (algae/detritus)

185 and space were depicted as nodes and the signs of the direct effects among them

186 were represented by directed links between the nodes. A link ending in an arrow

187 signified a positive direct effect, such as births produced through the consumption of

188 prey, whereas a link ending in a filled circle signified a negative one, such as deaths

189 from predation. A self-effect, as in self-thinning, was depicted as a link that starts and

190 ends at the same node.

191 Links were drawn based on functional relationships representing general

192 community assembly mechanisms and the expected role of each group in them. This

193 role was defined by the groups' assigned trait values and representative species

194 (Table 1). The functional relationships encompass processes of 1) environmental

195 filtering, 2) consumption of algae/detritus, 3) predation, 4) use of space, 5) food-

196 space competition trade-off, 6) early survival-colonization trade-off, 7) biogenic

197 habitat modification and 8) intra-group inhibition. Predation of benthos by fish and

198 birds was not included, because the former plays a limited role in the Rance estuary,

199 while the latter is highly seasonal and mostly restricted to the intertidal zone. 
In addition to the explicit representation of space as a basic resource (see section 2.3.4), implicit spatial considerations were required for the representation of a 202 few other processes (see sections 2.3.5-2.3.7). The modelled functional relationships represent interactions among populations of functional groups within an area that is 205 Intra-group spatial interactions were addressed independently (see section 2.3.8).

206

207

2.3.1

208

Environmental filtering

Epifaunal (T9) organisms with a preference for rock or gravel (T6) are clearly 210 distinguished from infaunal or interface-positioned organisms (T9) that prefer finer 211 sediment types (T6), with respect to both their functional characteristics (Alexandridis 212 et al., 2017) and their distribution patterns in the Rance estuary (see section S1 in the 213 Supplementary Material). This observation led to the drawing of two separate signed 214 digraphs for these two groups of organisms, signed digraph 1 (SD1) for the former, 215 epifaunal (Fig. 2a) and signed digraph 2 (SD2) for the latter, infaunal (Fig. 3a). Only 216 group C6 is part of both models, because of the high mobility (T10) and ambiguous 217 substrate preference (T6) of its species. The two sub-systems might co-occur but the 218 way in which they interact is not addressed here.

\section{$220 \quad 2.3 .2$}

221 Consumption of algae/detritus

222 Algae/detritus feeders along with predators/scavengers with the smallest 223 maximum size (T7) among all functional groups (groups C1 in SD1 and C4 in SD2) 224 are assumed to consume the basic food resource, either from the water column or 
225 through deposit feeding. This interaction was represented by a negative effect on 226 food and a positive effect on consumers (Fig. 2b, 3b). Group H2 in SD1 was excluded 227 from the consumption of the basic food resource, because of the grazing behaviour of 228 its representative species. The bulldozing effect of this behaviour, which is expected 229 to deprive other organisms of the free use of space (Pascual, 1997), was represented 230 by a consumption interaction with this resource.

\subsection{3}

Predation

The majority of predators appear to be larger than their prey, and predator size generally increases with the size of prey (Cohen et al., 1993). This general observation formed the assumption that groups of predators/scavengers (except for the smallest groups $\mathrm{C} 1$ and $\mathrm{C} 4$ ) can only feed on groups that are smaller or similar in maximum size (T7). Prey groups were, still, not allowed to be smaller than $1 / 3$ of the maximum size of the predator/scavenger groups themselves. The reason is that predator-prey body-size ratios are generally the lowest, just over 2 on average, for marine invertebrate predators, compared to predators of other taxonomic groups and habitat types, probably due to the energetic costs of prey capture and consumption (Brose et al., 2006a).

Predation was represented by a negative effect on prey and a positive effect on predators (Fig. 2c, 3c). The predator/scavenger group C5 in SD1 is represented by a sea anemone and its adult mobility (T10) is restricted, hence, only mobile functional groups were considered as its potential prey. Since all predator/scavenger groups are characterized as epifauna or interface-related (T9), infaunal functional groups (groups $\mathrm{H} 5, \mathrm{H} 6$ and $\mathrm{H} 12$ in SD2) along with groups whose representative species are 
250 protected by plates (groups $\mathrm{H} 2$ and $\mathrm{H} 3$ in SD1), shells (groups H4, H13 in SD1 and $251 \mathrm{H} 14$ in SD2) or tubes (groups $\mathrm{H} 7$ and $\mathrm{H} 11$ in SD2) were excluded from predator-prey 252 interactions.

\subsection{4}

255 Use of space

256 Just like food, space is assumed to be a basic resource that is "consumed" or 257 used by groups of algae/detritus feeders. Predators/scavengers (including sessile 258 group C5) are, instead, expected to only have their prey as their basic resource. In 259 addition to the aforementioned group H2, space in SD1 is also used by algae/detritus 260 feeders that are characterized as sessile (T10), since mobile organisms probably do 261 not have such a strong interaction with space.

In SD2, we expect the role of organisms in sediment engineering (T14) to play a central role in their interaction with space, with sediment stabilizers being primarily 264 limited by it. Organisms are also assumed to partition space, by occupying different 265 positions with respect to the substrate (T9). Since the two-dimensional nature of the 266 interface renders space particularly limiting for organisms that occupy this position, 267 we set space as a resource only for stabilizing groups of the interface. The use of space by these organisms was represented by a negative effect on space and a 269 positive effect on its consumers (Fig. 2d, 3d).

272 Food-space competition trade-off

273 In order to better represent differences in the functional roles of benthic 274 organisms in a way that is consistent with the general trade-offs that are expected to 
275 characterize these functional roles, we resorted again to the trait of maximum size 276 (T7). Higher levels of this trait are expected to confer a competitive advantage for 277 limited food resources, due to a larger area that can be searched for food or distance 278 from the substrate, which enhances the availability of food from the water column 279 (McLean and Lasker, 2013). On the other hand, maximum size (T7) appears to be 280 positively associated with the trait of minimum space requirement (T8) among benthic 281 macroinvertebrates of the Rance estuary (see section S2 in the Supplementary 282 Material). Higher values of the latter trait should confer a competitive disadvantage 283 for limited available space (Tilman 1980). We, thus, assumed that larger maximum 284 size (T7) represents a competitive advantage for food and disadvantage for space.

285 Based on this assumption, we divided the functional groups of each signed 286 digraph that consume the basic food resource in two categories, the small and the 287 big. We did so, by making sure that groups with similar sizes are placed in the same 288 category and that there are more small than large groups (Blackburn and Gaston, 289 1994). The members of each category are expected to be limited by the resource for 290 which they have a competitive disadvantage, while being able to efficiently reduce the 291 levels of the resource for which they are competitively superior. This set of 292 interactions was represented by an alteration of the existing resource consumption 293 interactions, so that a functional group receives a positive effect from its limiting 294 resource, while having a negative effect on the resource that it can efficiently reduce 295 (Fig. 2e, 3e). This rule was not applied to any groups that would otherwise appear not 296 to be limited by any of the basic resources, along with group H2 in SD1, whose 297 relationship with space represents its bulldozing effect on macroinvertebrate recruits. 
Early survival-colonization trade-off

We used three traits to represent life history trade-offs: early development mode 302 (T2), larval dispersal distance (T3) and maximum fecundity (T4). High levels for the 303 last two traits appear to be associated with planktonic early development (T2) among 304 benthic organisms in the Rance estuary, whereas low levels are associated with 305 brooded early development (T2) and high population growth rates (T11) (see section 306 S2 in the Supplementary Material). The former trait associations are expected to 307 result in higher colonization potential, whereas the latter can be linked to higher early 308 survival rates. The distinction between these groups of trait values represents a 309 trade-off among benthic organisms in the allocation of resources toward early survival 310 versus colonization potential (Tilman, 1990).

311 Functional groups with planktonic early development, long dispersal distance 312 and high fecundity are the only groups expected to effectively interact with the 313 resource of space, because of their high dispersal potential. The mobility of group $\mathrm{H} 2$ 314 in SD1 and its special relationship with space again excluded it from this rule. On the 315 other hand, functional groups with brooded early development should be able to 316 resist a variety of perturbations and, at least locally, reach high levels of abundance. 317 They were, therefore, depicted as able to reduce the resource of food, even if their 318 size did not qualify them to do so (Fig. 2f, 3f).

\subsection{7}

321 Biogenic habitat modification

322 The organisms that are represented by SD1 are distinguished from the rest by 323 their epifaunal position (T9) and requirement for hard substrate (T6) (see section S2 324 in the Supplementary Material). Their occurrence in the Rance estuary can be at 
325 least partly attributed to the phenomenon of epibiosis (T13), regardless of the 326 basibiotic organisms being alive or not (Wahl and Mark, 1999). The provision of hard 327 substrate by the single functional group that is described as basibiont (group H4) was

\subsection{8}

Intra-group inhibition

Negative self-effects were added to all variables of SD1 and SD2, representing a variety of processes (Fig. $2 \mathrm{~h}, 3 \mathrm{~h}$ ). In the case of the two basic resources, negative self-effects are mostly indicative of the existence of intrinsic limitations in the amounts that are available to their consumers. Negative self-effects for the rest of the variables can be the result of, among other things, crowding, behavioural inhibition of sessile predator/scavenger group C5 (Fig. 2g).

Substrate preferences among the organisms of SD2 (T6) appear to match their effect on the sediment (T14) (see section S2 in the Supplementary Material), in support of the mobility mode hypothesis and, hence, the separation of organisms into stabilizers and destabilizers (Posey, 1987). Sediment destabilization in the form of bioturbation should constitute the main mechanism of sediment engineering in estuarine soft bottoms (Meadows et al., 2012). Due to its high dispersal potential (T2, T3 and T4) and its role as a sediment destabilizer (T14), group H10 is expected to be mostly responsible for it. This group was, therefore, allowed to reduce the available space for stabilizing organisms of the interface and have a direct negative impact on infaunal stabilizers (groups $\mathrm{H} 6$ and $\mathrm{H} 12$ ). On the other hand, the ensuing bioirrigation is expected to generate favourable conditions for infaunal destabilizers and was depicted as a positive effect on group H5 (Fig. 3g). 


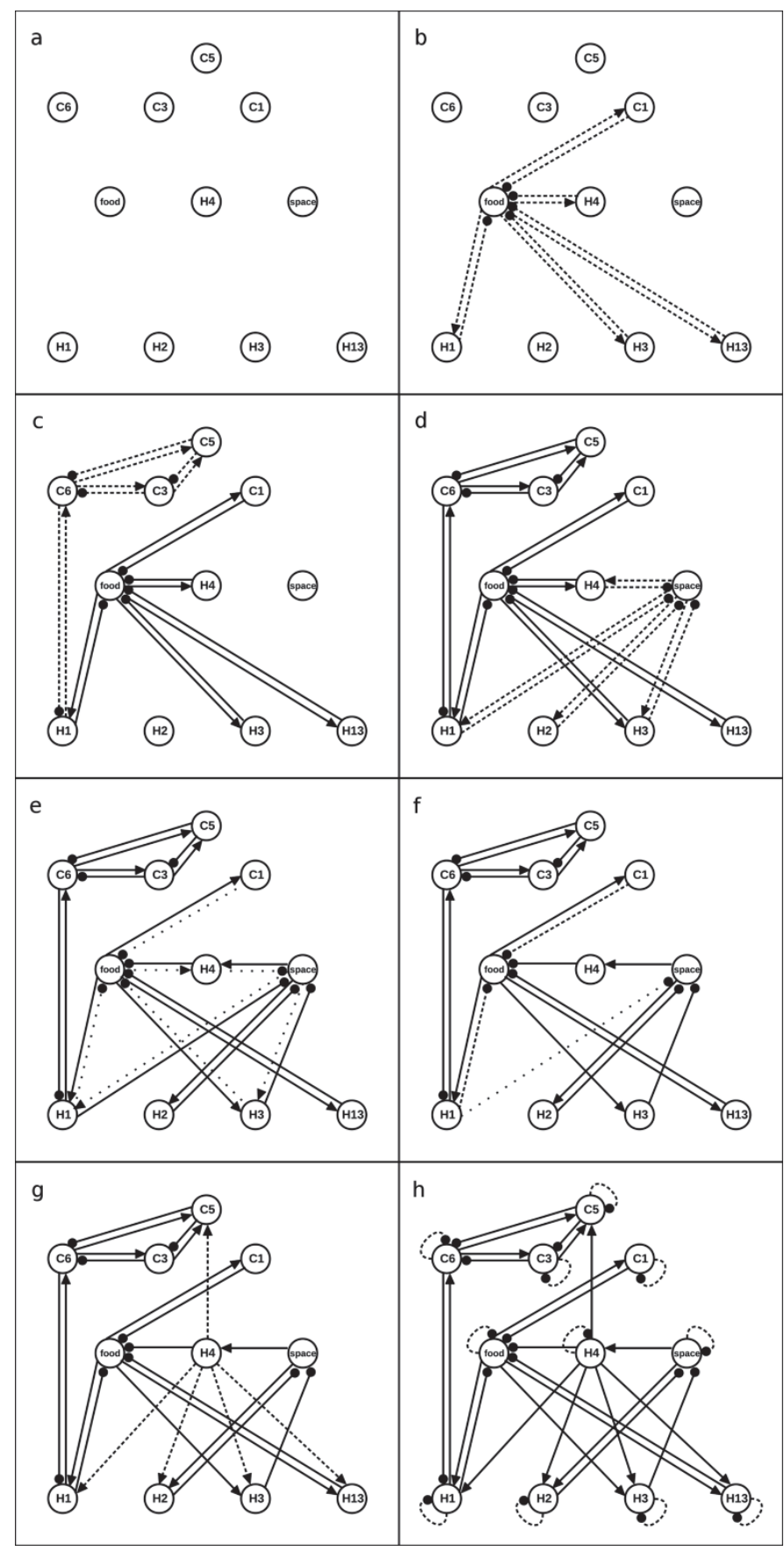

reproduction, territoriality or accumulation of waste products (Levins, 1998). These or

351 similar processes appear to be wide-spread in ecological systems (Connell, 1983). 352

354 Fig. 2. Stepwise drawing of signed digraph 1 (SD1, epifauna). The steps represent 355 processes of a) environmental filtering, b) consumption of algae/detritus, c) predation, 356 d) use of space, e) food-space competition trade-off, f) early survival-colonization 357 trade-off, g) epibiosis and h) intra-group inhibition. The nodes represent functional 
358 groups (see Table 1) or the basic resources of food and space. Links ending in

359 arrows and filled circles represent positive and negative direct effects, respectively.

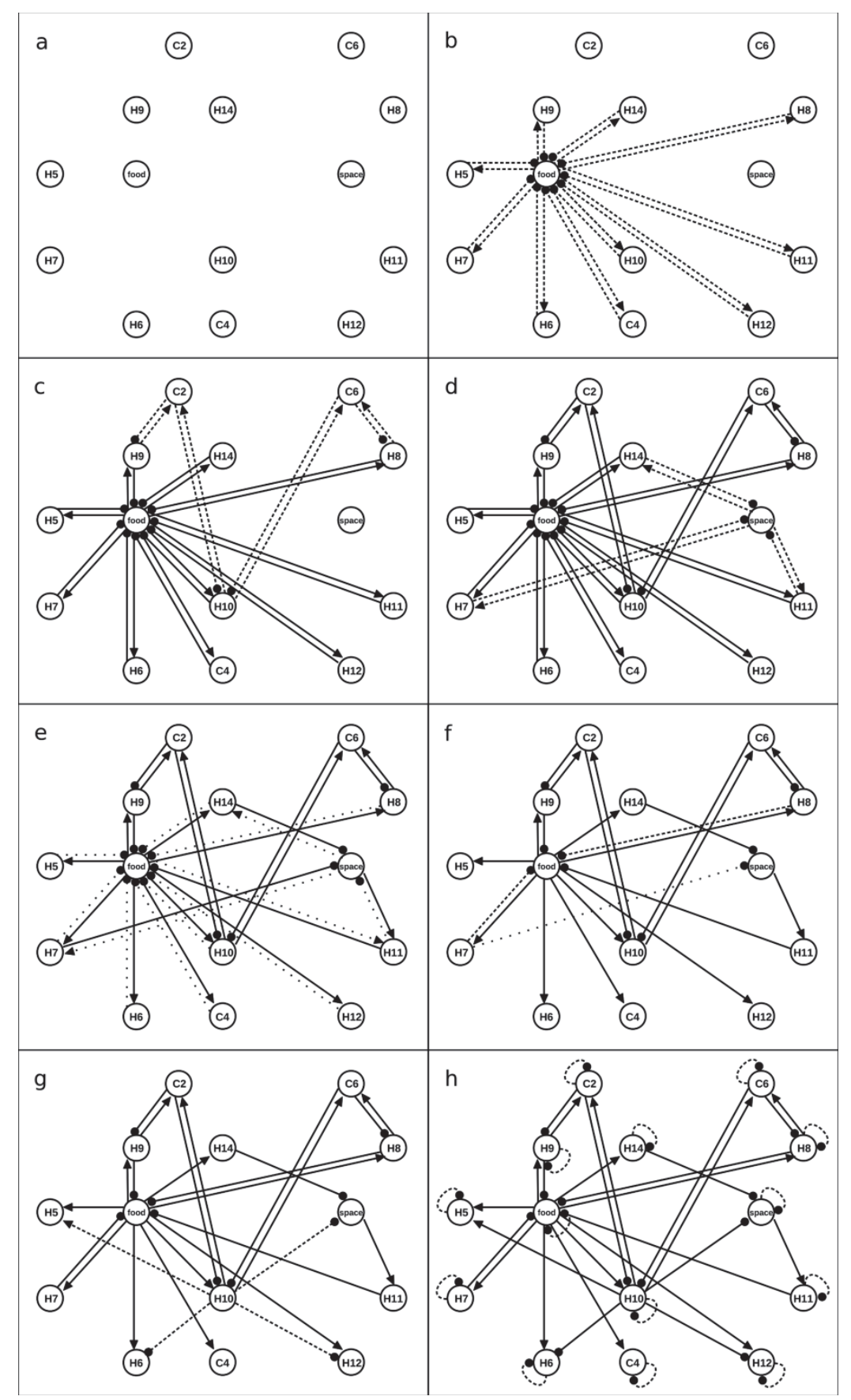

364 Fig. 3. Stepwise drawing of signed digraph 2 (SD2, infauna). The steps represent 365 processes of a) environmental filtering, b) consumption of algae/detritus, c) predation, 
d) use of space, e) food-space competition trade-off, f) early survival-colonization

367 trade-off, g) sediment engineering and h) intra-group inhibition. The nodes represent 368 functional groups (see Table 1) or the basic resources of food and space. Links ending in arrows and filled circles represent positive and negative direct effects, respectively. Dashed and dotted lines represent links that are added and removed, 371 respectively, at each step. See text for details

\section{4}

374 Feedback analysis

The concept of feedback in qualitatively specified systems, such as signed 376 digraphs, can be defined at different levels of a system, depending on the number of 377 interactions that are considered to participate in feedback cycles (i.e., closed paths of 378 interactions linking a subset of a system's variables without crossing any of them twice). Feedback cycles at level 1 are self effects, at level 2 they comprise pair-wise 380 interactions, such as predator-prey, with the highest level of feedback involving $n$

381 interactions in a model with $n$ variables. A cycle can consist of positive and negative 382 interactions and the product of their signs sets the overall sign of the cycle. In general 383 terms, negative feedback cycles provide stability and positive feedback cycles act to 384 destabilize a system (Puccia and Levins, 1985).

We assessed the potential for stability of our qualitative models as an indication 386 of the likelihood of the respective systems to exist in nature. To this end, we followed

387 the approach of Dambacher et al. (2003), who derived two criteria for the stability of 388 qualitative models, classified conditionally stable models accordingly and developed 389 stability metrics for each of the two model classes. The stability of class I models is 390 jeopardized by positive feedback dominating feedback at the highest level of a 
391 system. Instability in class II models is characterized by overcompensation, which

392 leads to oscillations, due to feedback at higher levels in a system overwhelming

393 feedback at lower levels. The latter case can be assessed by measuring the relative 394 balance of feedback at different system levels.

$395 \quad$ Most biological systems appear to be represented by class I models and their 396 potential for stability is determined by their maximum weighted feedback (Dambacher 397 et al., 2003). This metric is calculated by counting all feedback cycles (both positive 398 and negative) at the highest level of a system and computing the ratio of their net to absolute sums. It portrays the contribution of negative and positive feedback cycles to 400 the overall system feedback. Values that tend toward -1 indicate a high potential for 401 the variables of a system in equilibrium to converge toward their original levels 402 following a pulse perturbation. Values that tend toward 1 indicate a high potential for 403 post-perturbation divergence from these levels. Values near 0 show high ambiguity 404 with respect to the system's stability potential.

The classification of the models and the calculation of the stability metrics were 406 based on qualitatively specified community matrices, which are equivalent to signed 407 digraphs as a representation of a system. With the help of tools specifically designed 408 for their analysis (Dambacher et al., 2002), we assigned the qualitative models to one 409 of the two stability classes. Based on this classification, we calculated the metric that 410 quantifies each model's potential for stability. 
matrices (esapubs.org/archive/ecol/E083/022) using the technical computing

417 software Maple version 18.0 (Maplesoft, 2014).

420 Results

\section{$421 \quad 3.1$}

422 Signed digraphs

Building the signed digraphs of benthic macroinvertebrate communities in the Rance estuary left the epifaunal SD1 with 9 functional groups and the infaunal SD2 with 12, as group C6 participates in both models. In spite of having fewer groups, SD1 has 3 of them acting as predators, compared to only 2 predatory groups in SD2. Only 5 groups interact with algae/detritus in SD1 and 10 groups in SD2, while 3 groups interact with the basic resource of space in both models. The representation of the trade-off in competitive ability for food and space appears to have a deeper impact on the structure of the models than the trade-off between early survival and colonization potential. Incorporating the latter often resulted in a reversal of changes made to the models to represent the former. Biogenic habitat modification is of facilitating nature in SD1, taking the form of epibiosis, and of mostly inhibiting nature in SD2, where it represents bioturbation.

The qualitatively specified community matrices that correspond to SD1 (Table 3) and SD2 (Table 4) offer a detailed description of the interactions that comprise the two models. Of the 121 possible interactions in SD1 and the 196 possible interactions in SD2, only 36 occur in the former model and 41 in the latter. As a measure of system complexity, the proportion of possible interactions among each system's variables that are actually realized is equal to 0.29 in SD1 and 0.21 in SD2. SD1 
441 comprises 21 negative and 15 positive interactions, while SD2 has the same number 442 of positive interactions as SD1 and 26 negative.

444 Table 3. Qualitatively specified community matrix corresponding to SD1 (see Fig. 2). 445 Values along each column indicate negative (-), positive $(+)$ or absent $(0)$ direct 446 effects of the respective variable on the variables of the rows. The variables 447 represent functional groups (see Table 1) or the basic resources of food and space

\begin{tabular}{cccccccccccc}
\hline & food & space & $\mathrm{H} 1$ & $\mathrm{H} 2$ & $\mathrm{H} 3$ & $\mathrm{H} 4$ & $\mathrm{H} 13$ & $\mathrm{C} 1$ & $\mathrm{C} 3$ & $\mathrm{C} 6$ & $\mathrm{C} 5$ \\
\hline food & - & 0 & - & 0 & 0 & - & - & - & 0 & 0 & 0 \\
space & 0 & - & 0 & - & - & 0 & 0 & 0 & 0 & 0 & 0 \\
$\mathrm{H} 1$ & + & 0 & - & 0 & 0 & + & 0 & 0 & 0 & - & 0 \\
$\mathrm{H} 2$ & 0 & + & 0 & - & 0 & + & 0 & 0 & 0 & 0 & 0 \\
$\mathrm{H} 3$ & + & 0 & 0 & 0 & - & + & 0 & 0 & 0 & 0 & 0 \\
$\mathrm{H} 4$ & 0 & + & 0 & 0 & 0 & - & 0 & 0 & 0 & 0 & 0 \\
$\mathrm{H} 13$ & + & 0 & 0 & 0 & 0 & + & - & 0 & 0 & 0 & 0 \\
$\mathrm{C} 1$ & + & 0 & 0 & 0 & 0 & 0 & 0 & - & 0 & 0 & 0 \\
$\mathrm{C} 3$ & 0 & 0 & 0 & 0 & 0 & 0 & 0 & 0 & - & + & - \\
$\mathrm{C} 6$ & 0 & 0 & + & 0 & 0 & 0 & 0 & 0 & - & - & - \\
$\mathrm{C} 5$ & 0 & 0 & 0 & 0 & 0 & + & 0 & 0 & + & + & - \\
\hline
\end{tabular}

450 Table 4. Qualitatively specified community matrix corresponding to SD2 (see Fig. 3).

451 Values along each column indicate negative (-), positive $(+)$ or absent $(0)$ direct 452 effects of the respective variable on the variables of the rows. The variables 453 represent functional groups (see Table 1) or the basic resources of food and space

\begin{tabular}{|c|c|c|c|c|c|c|c|c|c|c|c|c|c|c|}
\hline & food & space & $\mathrm{H} 5$ & $\mathrm{HC}$ & $\mathrm{H} 14$ & $\mathrm{H} 8$ & $\mathrm{C} 2$ & C6 & $\mathrm{H} 6$ & $\mathrm{H} 7$ & $\mathrm{H} 10$ & $\mathrm{H} 11$ & $\mathrm{H} 12$ & C4 \\
\hline food & - & 0 & 0 & - & 0 & - & 0 & 0 & 0 & - & 0 & - & 0 & 0 \\
\hline
\end{tabular}




\begin{tabular}{lllllllllllllll}
$\mathrm{space}$ & 0 & - & 0 & 0 & - & 0 & 0 & 0 & 0 & 0 & - & 0 & 0 & 0 \\
$\mathrm{H} 5$ & + & 0 & - & 0 & 0 & 0 & 0 & 0 & 0 & 0 & + & 0 & 0 & 0 \\
$\mathrm{H} 9$ & + & 0 & 0 & - & 0 & 0 & - & 0 & 0 & 0 & 0 & 0 & 0 & 0 \\
$\mathrm{H} 14$ & + & 0 & 0 & 0 & - & 0 & 0 & 0 & 0 & 0 & 0 & 0 & 0 & 0 \\
$\mathrm{H} 8$ & + & 0 & 0 & 0 & 0 & - & 0 & - & 0 & 0 & 0 & 0 & 0 & 0 \\
$\mathrm{C} 2$ & 0 & 0 & 0 & + & 0 & 0 & - & 0 & 0 & 0 & + & 0 & 0 & 0 \\
$\mathrm{C} 6$ & 0 & 0 & 0 & 0 & 0 & + & 0 & - & 0 & 0 & + & 0 & 0 & 0 \\
$\mathrm{H} 6$ & + & 0 & 0 & 0 & 0 & 0 & 0 & 0 & - & 0 & - & 0 & 0 & 0 \\
$\mathrm{H} 7$ & + & 0 & 0 & 0 & 0 & 0 & 0 & 0 & 0 & - & 0 & 0 & 0 & 0 \\
$\mathrm{H} 10$ & + & 0 & 0 & 0 & 0 & 0 & - & - & 0 & 0 & - & 0 & 0 & 0 \\
$\mathrm{H} 11$ & 0 & + & 0 & 0 & 0 & 0 & 0 & 0 & 0 & 0 & 0 & - & 0 & 0 \\
$\mathrm{H} 12$ & + & 0 & 0 & 0 & 0 & 0 & 0 & 0 & 0 & 0 & - & 0 & - & 0 \\
$\mathrm{C} 4$ & + & 0 & 0 & 0 & 0 & 0 & 0 & 0 & 0 & 0 & 0 & 0 & 0 & - \\
\hline
\end{tabular}

457 Feedback analysis

The results of the stability analysis for the qualitatively specified community 459 matrices that correspond to SD1 and SD2 are shown in Table 5. The pattern of 460 increasing weighted feedback with increasing system level for both models indicates 461 that their stability could be compromised by positive feedback dominating feedback at 462 the highest level of the system rather than by overcompensation; SD1 and SD2 are, 463 therefore, class I models (sensu Dambacher et al. (2003)). Consequently, their 464 potential for stability is determined by their maximum weighted feedback, which 465 quantifies the contribution of negative and positive feedback cycles to the overall 466 system feedback. This metric is well below 0 for both models, indicating the 
467 dominance of negative feedback cycles over positive ones, along with a moderate

468 level of ambiguity with respect to the stability potential of the system.

470 Table 5 . Results of the stability analysis for the systems represented by SD1 (see

471 Fig. 2) and SD2 (see Fig. 3). Values along each row correspond to weighted

472 feedback (wF) calculated at the system level that is indicated by the ensuing number.

473 The value of maximum weighted feedback for each model is indicated by an asterisk

\begin{tabular}{ccccccccccccccc}
\hline & $w F 1$ & $w F 2$ & $w F 3$ & $w F 4$ & $w F 5$ & $w F 6$ & $w F 7$ & $w F 8$ & $w F 9$ & $w F 10$ & $w F 11$ & $w F 12$ & $w F 13$ & $w F 14$ \\
\hline SD1 & -1 & -1 & -0.99 & -0.97 & -0.94 & -0.9 & -0.83 & -0.75 & -0.66 & -0.57 & $-0.5^{*}$ & - & - & - \\
SD2 & -1 & -1 & -1 & -0.99 & -0.98 & -0.95 & -0.9 & -0.84 & -0.77 & -0.69 & -0.6 & -0.51 & -0.42 & $-0.33^{*}$ \\
\hline
\end{tabular}

474

475

In both SD1 and SD2, the basic resources of food and space are part of positive 477 feedback cycles of length four. In the case of SD1, the positive feedback cycle is 478 formed with groups H3 and H4 (Fig. 4a). The former, being small, is enhanced by 479 food and reduces space, while the latter, being big, plays the opposite role. In SD2 480 there are two equivalent positive feedback cycles (Fig. 4b). Each of them is formed 481 with one of the small groups $\mathrm{H} 10$ and $\mathrm{H} 14$, which are enhanced by food and reduce 482 space, along with big group $\mathrm{H} 11$, which plays the opposite role. Due to the self483 enhancing nature of positive feedback cycles, variables are likely to respond to long484 term perturbations in a correlated manner. Food quantity and the abundances of 485 small groups $\mathrm{H} 3, \mathrm{H} 10$ and $\mathrm{H} 14$ would shift in the same direction, opposite to the 486 amount of available space and the abundances of big groups $\mathrm{H} 4$ and $\mathrm{H} 11$. 

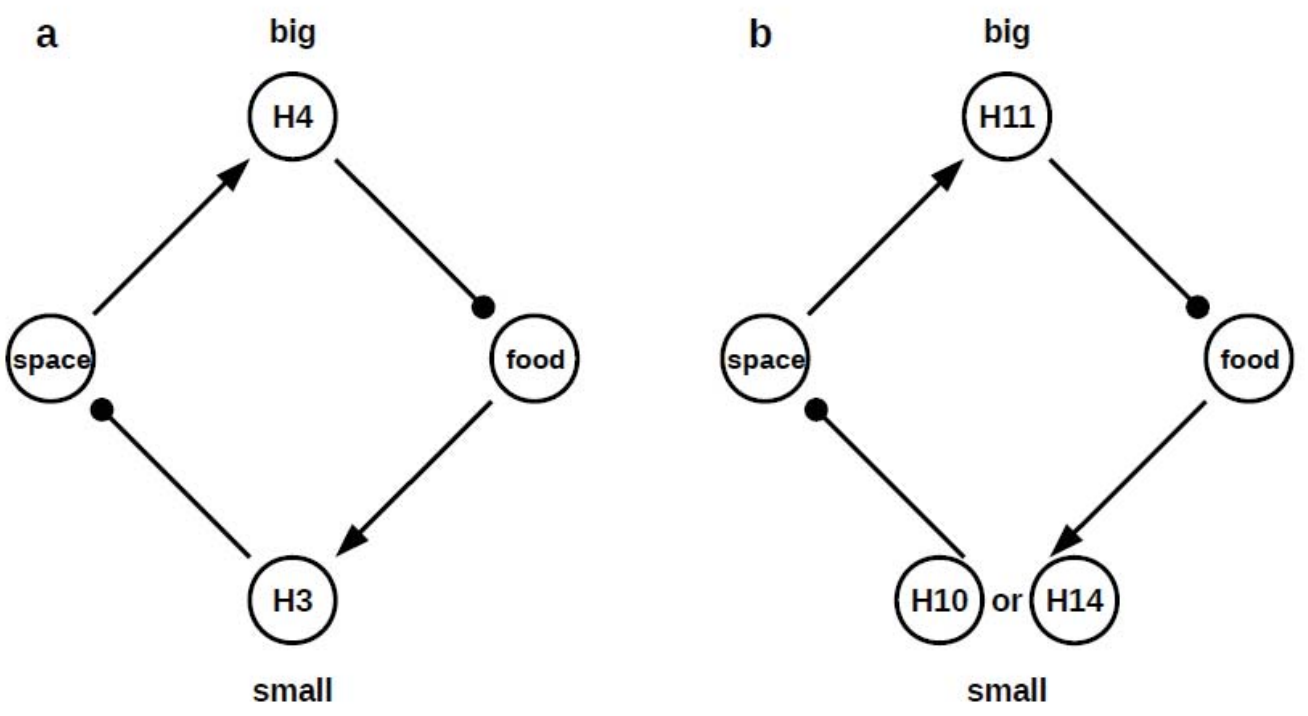

489 Fig. 4. Positive feedback cycles from a) SD1 (see Fig. 2) and b) SD2 (see Fig. 3). 490 Each feedback cycle links the basic resources of food and space with one big and 491 one small functional group. Links ending in arrows and filled circles represent positive 492 and negative direct effects, respectively

495 Discussion

$496 \quad 4.1$

497 Functional groups

498 Qualitatively specified food-web models often represent only a few dominant 499 species of marine benthic macroinvertebrates, while other community members may 500 be grouped into broad trophic categories (e.g., Carey et al., 2014; Reum et al., 2015). 501 This practice cannot explicitly account for key non-trophic interactions and tends to 502 ignore the rarest members of a community, in spite of evidence for their significant 503 contribution to ecosystem functioning (Lyons et al., 2005). This contribution can be 
504 disproportionate to their abundance, as species with the most distinct combinations of

505 traits have been shown to be rarer than expected by chance (Mouillot et al., 2013).

506 The variables of the models developed here were built through a procedure that 507 places emphasis on the species' functional role instead of their abundance; the latter 508 is used only secondarily for the assignment of trait values to each group (Alexandridis 509 et al., 2017). The wide functional scope of the traits that formed the basis for the

510 grouping allowed the representation of not just trophic interactions, but the majority of the mechanisms that are expected to shape benthic communities in many parts of the world. Trait variation within the groups was found to be largely neutral, allowing a system representation that is free of functionally equivalent variability (Hérault, 2007).

\section{2}

516 Signed digraphs

The evaluation of the functional grouping against its theoretical assumptions suggested that species abundances in the Rance estuary depend, at least to some extent, on species trait values (Alexandridis et al., 2017). The nature of this knowledge to define functional relationships between the groups and their basic

\section{4 resources.}

Each of the community assembly mechanisms that are represented by these 526 relationships encompasses a variety of processes that could potentially be 527 represented much more explicitly. The level at which each mechanism was actually represented was dictated by the available trait and environmental information. Hence, 
529 biological traits were used as proxies for the role of functional groups in a set of

530 theoretically expected community assembly mechanisms that were illustrated through

For instance, the biogeochemical aspects of sediment engineering were not 533 explicitly represented, as the distinction between sediment stabilizers and 534 destabilizers (Posey, 1987) was the best possible representation, given the available 535 information at the species level. Still, this tenet of the mobility-mode hypothesis has 536 been empirically upheld and shown to have cascading and long-lasting effects on benthic communities (Volkenborn et al., 2009). Similarly, the complex set of processes that comprise the phenomenon of resource competition was only represented through the use of each group's maximum size in the context of the concentration reduction hypothesis for space and food (Tilman, 1980). Space limitation due to adult-juvenile interactions and exploitative competition for food have been shown to play a central role in the successional dynamics of benthic communities, with the functional role of organisms largely defined by their size (Van Colen et al., 2008). The combined representation of food and space as limiting resources can significantly increase our understanding and predictability of marine benthic systems (Svensson and Marshall, 2015).

The separation of benthic macroinvertebrates into algae/detritus feeders and predators/scavengers aimed to preserve the homogeneity of their resource base, so 552 has been, however, shown that feeding behaviour in the marine benthos is highly 553 facultative and similar categorizations are not always valid (Snelgrove and Butman, 
554 1994). Instead, the modification of networks of trophic interactions through expert

555 knowledge is expected to increase their realism, while the use of allometric scaling 556 should enhance their stability (Brose et al., 2006b).

Survival rates (Schratzberger and Larcombe, 2014) and colonization potential 558 (Limberger and Wickham, 2011) have been separately involved in trade-offs with the

competitive ability of benthic organisms. Our assumptions allow for both scenarios, while the deconstruction of competitive ability into two constituents, for the basic resources of food and space, could resolve inconsistencies in previous findings. under-represented. Biological traits related to species' reproductive strategy were found to deviate the most from the theoretical assumptions that allowed the construction of the functional groups (Alexandridis et al., 2017). Relevant trait information is, however, consistently lacking (Tyler et al., 2012). A more accurate depiction of recruitment-related processes would allow the explicit representation of trade-offs that have been shown to play a significant role in the assembly of benthic communities (Lindquist and Hay, 1996; Marshall and Steinberg, 2014).

The functional divergence between organisms that occupy the surface of the sediment (epifauna) and those that are buried in it (infauna) has been previously recognized in the study of marine benthos (Reiss et al., 2010). In the Rance estuary, 573 the epifauna (SD1) features a lower functional diversity of algae/detritus feeders and 574 a higher functional diversity of predators/scavengers, compared to the infauna (SD2). 575 Additionally, a much higher number of groups ended up interacting with algae/detritus 576 in SD2 compared to SD1. The complex diagenetic processes that affect the basic 577 food resource within the sediment of the seafloor (Herman et al., 1999) could be 578 responsible for the diversity of infaunal organisms that feed on it. On the other hand, 
579 the high structural complexity of the habitat occupied by epifaunal organisms may 580 result in a higher diversity of predatory strategies. Trophic differences could be 581 associated with a variety of biological traits, leading to observed patterns of functional

585 system. The qualitatively antithetical role of biogenic habitat modification in the two

\section{3}

Feedback analysis

The results of the stability analysis suggest that the models developed in this work have a moderate to high potential for stability. This demonstrates the likelihood of the system to persist in time in spite of perturbations. These perturbations can take various forms, from local sediment re-suspension due to wave action, to system-wide reduction of secondary production during extremely cold winters (Desroy, 1998). Despite the impact of such pulse perturbations on spatial and temporal distribution patterns of benthic macroinvertebrates, the composition of their communities has been mostly stable in the Rance estuary since late 1970's. The agreement between observed stability levels and the predictions of feedback analysis can be considered 02 as partial validation of the generated models. 
Populations of benthic macroinvertebrates in the Rance estuary are still 604 expected to change in response to constant or press perturbations, but in a way that can be attributed to the structure of the qualitative models. For instance, the participation of the basic resource of food in positive feedback cycles in both SD1 and SD2 allows the formulation of predictions about the direction in which the other 608 variables in these cycles would respond as a result of system-wide persistent changes in primary production. Within these cycles, which constitute a qualitative representation of Tilman's (1980) concentration reduction hypothesis, a decrease in the amount of available food is expected, in general, to lead to less smaller and more

613 Similar patterns have been observed as a result of bathymetric decreases in nutrient 614 input (Rex and Etter, 1998) and can have profound impacts on the functioning of 615 ecological systems (Woodward et al., 2005).

618 Conclusions

619 Qualitative mathematical models have been successfully employed for the study 620 of both soft- (Ortiz and Wolff, 2002) and hard-bottom (Marzloff et al., 2011) marine 621 benthos. The properties of these models make them particularly well-suited for the 622 integration of systems that comprise processes of disparate nature (Dambacher et 623 al., 2007). Our approach primarily differs from previous work in the way organisms 624 are represented and interactions are attributed between them. This is done through a 625 systematic procedure that employs theoretical and expert knowledge from a wide 626 range of sources. It can be applied, with adjustments of various degrees, for the 
627 mechanistic representation of many ecological systems for which empirical 628 information is limited.

Qualitative models sacrifice the element of precision, in order to produce a

Acknowledgments: We thank Claire Chevalier, Stanislas F. Dubois, Antoine Carlier and Patrick Le Mao for sharing their knowledge of the system and assisting in the collection of biological traits information. We are also grateful to the editor and plant (Boulangeat et al., 2014) and animal communities (Scherer et al., 2016) to projected climatic and land use change. They faced issues that are shared by our study, such as the lack of information on important biological traits or the limited potential for validating model predictions with species data. Quite similar to our study, they addressed these issues by using surrogate traits or investigating the plausibility of their findings in view of specific system perturbations. The conclusion of our work should help bridge the gap between terrestrial and marine systems with regard to the formulation of reliable predictions of biodiversity responses to environmental change. general and realistic representation of the causal relationships that shape a system (Levins, 1966). When there is uncertainty in the model components or interactions, alternative model configurations can be easily generated and assessed with respect to the functioning of the system (Dambacher et al., 2002). Qualitative modelling can, therefore, direct the initial steps of more quantitative approaches, before investment in model development has rendered structural changes too costly. We plan to use this property to inform the structure of dynamic and spatially explicit trait-based models of marine benthic communities in the Rance estuary (Alexandridis, 2017).

Similar efforts in terrestrial environments were able to predict the responses of 
651 anonymous reviewers for comments that substantially improved the manuscript. This

work was supported by LabexMer French project (ANR-10-LABX-19-01).

References

Alexandridis, N., 2017. Models of general community assembly mechanisms simulating the spatial and temporal dynamics of benthic biodiversity. PhD 656

Thesis. Université de Bretagne Occidentale, Brest, France.

\section{http://archimer.ifremer.fr/doc/00383/49481/}

Alexandridis, N., Bacher, C., Desroy, N., Jean, F., 2017. Building functional groups of 660 marine benthic macroinvertebrates on the basis of general community assembly mechanisms. J. Sea Res. 121, 59-70.

Amarasekare, P., 2003. Competitive coexistence in spatially structured environments: a synthesis. Ecol. Lett. 6, 1109-1122.

Berlow, E.L., Dunne, J.A., Martinez, N.D., Stark, P.B., Williams, R.J., Brose, U., 2009. Simple prediction of interaction strengths in complex food webs. P. Natl. Acad. Sci. USA 106, 187-191.

Blackburn, T.M., Gaston, K.J., 1994. Animal body size distributions: patterns, mechanisms and implications. Trends Ecol. Evol. 9, 471-474.

Bonnot-Courtois, C., Lafond, L.R., 1991. Caractérisation et comportement des vases dans l'estuaire de la Rance. Rapport EDF. EPHE, Dinard, France.

Boulangeat, I., Georges, D., Thuiller, W., 2014. FATE-HD: a spatially and temporally explicit integrated model for predicting vegetation structure and diversity at regional scale. Glob. Change Biol. 20, 2368-2378.

Boulangeat, I., Philippe, P., Abdulhak, S., Douzet, R., Garraud, L., Lavergne, S., Lavorel, S., van Es, J., Vittoz, P., Thuiller, W., 2012. Improving plant functional 
groups for dynamic models of biodiversity: at the crossroads between functional and community ecology. Glob. Change Biol. 18, 3464-3475.

Brose, U., Jonsson, T., Berlow, E.L., Warren, P., Banasek-Richter, C., Bersier, L.F., Blanchard, J.L., Brey, T., Carpenter, S.R., Blandenier, M.F.C., Cushing, L., Dawah, H.A., Dell, T., Edwards, F., Harper-Smith, S., Jacob, U., Ledger, M.E., Martinez, N.D., Memmott, J., Mintenbeck, K., Pinnegar, J.K., Rall, B.C., Rayner, T.S., Reuman, D.C., Ruess, L., Ulrich, W., Williams, R.J., Woodward, G., Cohen, J.E., 2006a. Consumer-resource body-size relationships in natural food webs. Ecology 87, 2411-2417.

Brose, U., Williams, R.J., Martinez, N.D., 2006b. Allometric scaling enhances stability in complex food webs. Ecol. Lett. 9, 1228-1236.

Cardinale, B.J., Duffy, J.E., Gonzalez, A., Hooper, D.U., Perrings, C., Venail, P., Narwani, A., Mace, G.M., Tilman, D., Wardle, D.A., Kinzig, A.P., Daily, G.C., Loreau, M., Grace, J.B., Larigauderie, A., Srivastava, D.S., Naeem, S., 2012. Biodiversity loss and its impact on humanity. Nature 486, 59-67.

Carey, M.P., Levin, P.S., Townsend, H., Minello, T.J., Sutton, G.R., Francis, T.B., Harvey, C.J., Toft, J.E., Arkema, K.K., Burke, J.L., Kim, C.K., Guerry, A.D., Plummer, M., Spiridonov, G., Ruckelshaus, M., 2014. Characterizing coastal foodwebs with qualitative links to bridge the gap between the theory and the practice of ecosystem-based management. ICES J. Mar. Sci. 71, 713-724.

Cattin, M.F., Bersier, L.F., Banasek-Richter, C., Baltensperger, R., Gabriel, J.P., 2004. Phylogenetic constraints and adaptation explain food-web structure. Nature 427, 835-839.

Chesson, P., 2000. Mechanisms of maintenance of species diversity. Annu. Rev. Ecol. Syst. 31, 343-366. 
Cohen, J.E., Newman, C.M., 1985. A stochastic theory of community food webs. I.

703 Cohen, J.E., Pimm, S.L., Yodzis, P., Saldaña, J., 1993. Body sizes of animal 704 predators and animal prey in food webs. J. Anim. Ecol. 62, 67-78.

705 Connell, J.H., 1983. On the prevalence and relative importance of interspecific $706 \quad$ competition: evidence from field experiments. Am. Nat. 122, 661-696.

707 Constable, A.J., 1999. Ecology of benthic macro-invertebrates in soft-sediment 708

environments: A review of progress towards quantitative models and predictions. Aust. J. Ecol. 24, 452-476.

Costanza, R., d'Arge, R., de Groot, R., Farber, S., Grasso, M., Hannon, B., Limburg, K., Naeem, S., O’Neill, R.V., Paruelo, J., Raskin, R.G., Sutton, P., van den Belt, M., 1998. The value of the world's ecosystem services: putting the issues in perspective. Ecol. Econ. 25, 67-72.

Dambacher, J.M., Brewer, D.T., Dennis, D.M., Macintyre, M., Foale, S., 2007. Qualitative modelling of gold mine impacts on Lihir island's socioeconomic system and reef-edge fish community. Environ. Sci. Technol. 41, 555-562.

Dambacher, J.M., Li, H.W., Rossignol, P.A., 2002. Relevance of community structure in assessing indeterminacy of ecological predictions. Ecology 83, 1372-1385.

Dambacher, J.M., Luh, H.K., Li, H.W., Rossignol, P.A., 2003. Qualitative stability and ambiguity in model ecosystems. Am. Nat. 161, 876-888.

Desroy, N., 1998. Les peuplements benthiques de substrats meubles du bassin maritime de la Rance. Évolution de la biodiversité et effets de l'activité prédatrice de Nephtys hombergii (Annélide Polychète). PhD Thesis. Université de Rennes 1, Rennes, France. 
725 Fath, B.D., 2004. Network analysis applied to large-scale cyber-ecosystems. Ecol. Model. 171, 329-337.

Halnes, G., Fath, B.D., Liljenström, H., 2007. The modified niche model: including detritus in simple structural food web models. Ecol. Model. 208, 9-16.

Hérault, B., 2007. Reconciling niche and neutrality through the Emergent Group approach. Perspect. Plant Ecol. 9, 71-78.

Herman, P., Middelburg, J., Van de Koppel, J., Heip, C., 1999. Ecology of estuarine macrobenthos. Adv. Ecol. Res. 29, 195-240.

Ings, T.C., Montoya, J.M., Bascompte, J., Blüthgen, N., Brown, L., Dormann, C.F., Edwards, F., Figueroa, D., Jacob, U., Jones, J.I., Lauridsen, R.B., Ledger, M.E., Lewis, H.M., Olesen, J.M., van Veen, F.J.F., Warren, P.H., Woodward, G., 2009. Ecological networks - beyond food webs. J. Anim. Ecol. 78, 253-269.

Jetz, W., Carbone, C., Fulford, J., Brown, J.H., 2004. The scaling of animal space use. Science 306, 266-268.

Kearney, M., Porter, W., 2009. Mechanistic niche modelling: combining physiological and spatial data to predict species' ranges. Ecol. Lett. 12, 334-350.

Kéfi, S., Berlow, E.L., Wieters, E.A., Navarrete, S.A., Petchey, O.L., Wood, S.A., Boit, A., Joppa, L.N., Lafferty, K.D., Williams, R.J., Martinez, N.D., Menge, B.A., Blanchette, C.A., Iles, A.C., Brose, U., 2012. More than a meal... integrating non-feeding interactions into food webs. Ecol. Lett. 15, 291-300.

Levins, R., 1998. Qualitative mathematics for understanding, prediction, and intervention in complex ecosystems. In: Ecosystem Health. Blackwell Science, Oxford, UK.

Levins, R., 1966. The strategy of model building in population biology. Am. Sci. 54, $421-431$. 
750 Limberger, R., Wickham, S.A., 2011. Competition-colonization trade-offs in a ciliate model community. Oecologia 167, 723-732.

McLean, E.L., Lasker, H.R., 2013. Height matters: position above the substratum influences the growth of two demosponge species. Mar. Ecol. 34, 122-129.

Meadows, P.S., Meadows, A., Murray, J.M.H., 2012. Biological modifiers of marine benthic seascapes: their role as ecosystem engineers. Geomorphology 157158, 31-48.

Morris, J.T., Christian, R.R., Ulanowicz, R.E., 2005. Analysis of size and complexity of randomly constructed food webs by information theoretic metrics. In: Belgrano, A., Scharler, U.M., Dunne, J., Ulanowicz, R.E. (Eds.), Aquatic food webs: an ecosystem approach. Oxford University Press, Oxford, UK.

Mouillot, D., Bellwood, D.R., Baraloto, C., Chave, J., Galzin, R., Harmelin-Vivien, M., Kulbicki, M., Lavergne, S., Lavorel, S., Mouquet, N., Paine, T.C.E., Renaud, J., Thuiller, W., 2013. Rare species support vulnerable functions in high-diversity ecosystems. PLOS Biol. 11, e1001569. 
775 Ortiz, M., Wolff, M., 2002. Application of loop analysis to benthic systems in northern

778

Chile for the elaboration of sustainable management strategies. Mar. Ecol.-Prog. Ser. 242, 15-27.

Pascual, M.S., 1997. Carriage of dwarf males by adult female puelche oysters: the role of chitons. J. Exp. Mar. Biol. Ecol. 212, 173-185.

Pereira, H.M., Leadley, P.W., Proença, V., Alkemade, R., Scharlemann, J.P.W., Fernandez-Manjarrés, J.F., Araújo, M.B., Balvanera, P., Biggs, R., Cheung, W.W.L., Chini, L., Cooper, H.D., Gilman, E.L., Guénette, S., Hurtt, G.C., Huntington, H.P., Mace, G.M., Oberdorff, T., Revenga, C., Rodrigues, P., Scholes, R.J., Sumaila, U.R., Walpole, M., 2010. Scenarios for global biodiversity in the 21st century. Science 330, 1496-1501.

Petchey, O.L., Beckerman, A.P., Riede, J.O., Warren, P.H., 2008. Size, foraging, and food web structure. P. Natl. Acad. Sci. USA 105, 4191-4196.

Petchey, O.L., Gaston, K.J., 2006. Functional diversity: back to basics and looking forward. Ecol. Lett. 9, 741-758.

Pineda, J., Reyns, N.B., Starczak, V.R., 2009. Complexity and simplification in understanding recruitment in benthic populations. Popul. Ecol. 51, 17-32.

Posey, M.H., 1987. Influence of relative mobilities on the composition of bentic communities. Mar. Ecol.-Prog. Ser. 39, 99-104.

Puccia, C.J., Levins, R., 1985. Qualitative modeling of complex systems. Harvard University Press, Cambridge, USA.

Queirós, A.M., Bruggeman, J., Stephens, N., Artioli, Y., Butenschön, M., Blackford, J.C., Widdicombe, S., Allen, J.I., Somerfield, P.J., 2015. Placing biodiversity in ecosystem models without getting lost in translation. J. Sea Res. 98, 83-90. 
799 Reiss, H., Degraer, S., Duineveld, G.C.A., Kröncke, I., Aldridge, J., Craeymeersch, J.A., Eggleton, J.D., Hillewaert, H., Lavaleye, M.S.S., Moll, A., Pohlmann, T., Rachor, E., Robertson, M., Vanden Berghe, E., van Hoey, G., Rees, H.L., 2010. Spatial patterns of infauna, epifauna, and demersal fish communities in the North Sea. ICES J. Mar. Sci. 67, 278-293.

Retière, C., 1994. Tidal power and the aquatic environment of La Rance. Biol. J. Linn. Soc. $51,25-36$.

Reum, J.C.P., McDonald, P.S., Ferriss, B.E., Farrell, D.M., Harvey, C.J., Levin, P.S., 2015. Qualitative network models in support of ecosystem approaches to bivalve aquaculture. ICES J. Mar. Sci. 72, 2278-2288.

Rex, M.A., Etter, R.J., 1998. Bathymetric patterns of body size: implications for deepsea biodiversity. Deep-Sea Res. Pt. II 45, 103-127.

Robinson, L.A., Greenstreet, S.P.R., Reiss, H., Callaway, R., Craeymeersch, J., de Boois, I., Degraer, S., Ehrich, S., Fraser, H.M., Goffin, A., Kröncke, I., Jorgenson, L.L., Robertson, M.R., Lancaster, J., 2010. Length-weight relationships of 216 North Sea benthic invertebrates and fish. J. Mar. Biol. Assoc. UK 90, 95-104.

Savage, V.M., Gillooly, J.F., Brown, J.H., West, G.B., Charnov, E.L., 2004. Effects of body size and temperature on population growth. Am. Nat. 163, 429-441.

Scherer, C., Jeltsch, F., Grimm, V., Blaum, N., 2016. Merging trait-based and individual-based modelling: An animal functional type approach to explore the responses of birds to climatic and land use changes in semi-arid African savannas. Ecol. Model. 326, 75-89.

Schratzberger, M., Larcombe, P., 2014. The role of the sedimentary regime in shaping the distribution of subtidal sandbank environments and the associated 
meiofaunal nematode communities: an example from the southern North Sea. PLoS ONE 9, e109445.

Snelgrove, P.V.R., Butman, C.A., 1994. Animal-sediment relationships revisited: cause versus effect. Oceanogr. Mar. Biol. 32, 111-177.

Solan, M., Germano, J.D., Rhoads, D.C., Smith, C., Michaud, E., Parry, D., Wenzhöfer, F., Kennedy, B., Henriques, C., Battle, E., Carey, D., locco, L., Valenete, R., Watson, J., Rosenberg, R., 2003. Towards a greater understanding of pattern, scale and process in marine benthic systems: a picture is worth a thousand worms. J. Exp. Mar. Biol. Ecol. 285-286, 313-338.

Sutherland, W.J., Freckleton, R.P., Godfray, H.C.J., Beissinger, S.R., Benton, T., Cameron, D.D., Carmel, Y., Coomes, D.A., Coulson, T., Emmerson, M.C., Hails, R.S., Hays, G.C., Hodgson, D.J., Hutchings, M.J., Johnson, D., Jones, J.P.G., Keeling, M.J., Kokko, H., Kunin, W.E., Lambin, X., Lewis, O.T., Malhi, Y., Mieszkowska, N., Milner-Gulland, E.J., Norris, K., Phillimore, A.B., Purves, D.W., Reid, J.M., Reuman, D.C., Thompson, K., Travis, J.M.J., Turnbull, L.A., Wardle, D.A., Wiegand, T., 2013. Identification of 100 fundamental ecological questions. J. Ecol. 101, 58-67.

Svensson, J.R., Marshall, D.J., 2015. Limiting resources in sessile systems: food enhances diversity and growth of suspension feeders despite available space. Ecology 96, 819-827.

Tilman, D., 1990. Constraints and tradeoffs: toward a predictive theory of competition and succession. Oikos 58, 3-15.

Tilman, D., 1980. Resources: a graphical-mechanistic approach to competition and predation. Am. Nat. 116, 362-393. 
Tyler, E.H.M., Somerfield, P.J., Berghe, E.V., Bremner, J., Jackson, E., Langmead, 


\section{SUPPLEMENTARY MATERIAL}

\section{S.1 Environmental filtering}

\section{S.1.1 Methods}

Each station sampled in the spring of 1995 was associated with a particular sediment type (pure mud, mud, silty mud, sandy mud, muddy sand, fine/intermediate sand, intermediate/coarse sand, coarse sand, gravel), based on a sedimentary map established in 1994 (Bonnot-Courtois, 1997). The depth (or elevation) of each station was measured at low tide during the collection of samples. Each station was assigned a salinity regime, depending on which of three sectors of the Rance estuary it was situated in. The innermost part of the estuary, up to Pleudihen-sur-Rance, was subject to high salinity variation, ranging from 0.5 to 30. Beyond this point, downstream to Port-St-Hubert, salinity values ranged between 18 and 30. The rest of the estuary experienced more or less constant salinity levels, over the value of 30, similar to those of the open sea (Desroy, 1998).

Among the 14 biological traits for which the species of the system were assigned with values, we expect the trait of tolerance to tidal emersion and low salinity levels (T5) along with that of preferred substrate type (T6) to adequately represent the most important environmental limitations that are faced by benthic macroinvertebrates in the Rance estuary (Desroy, 1998). If this is indeed the case, these two biological traits, describing species preference for abiotic conditions, should show high degrees of covariation with the respective environmental variables. Other biological traits that might correlate with the two traits in question are also expected to show similar patterns of covariation.

RLQ analysis is a statistical technique that can relate the biological traits of organisms to the characteristics of the environment in which they live (Dolédec et al., 1996). L refers to a table of species abundance at a number of sites and it describes, among other things, the actual habitat utilization of different species. $\mathrm{R}$ refers to a table of environmental variables measured at the same sites as species abundance. Q refers to a table of biological traits for all the species of table L. RLQ analysis starts with the separate ordination of table L. It then uses the resulting sites and species weights in the separate ordinations of tables $\mathrm{R}$ and $\mathrm{Q}$, respectively. The result is an ordination of the common structure of tables $\mathrm{R}$ and $\mathrm{Q}$ with a link expressed by table L.

Since environmental variables and biological traits include both qualitative and quantitative information, we opted for Hill and Smith analysis (Hill and Smith, 1976) for the separate ordinations of the 113 sites $\times 3$ environmental variables $(R)$ and the 240 species $\times 14$ biological traits (Q) tables. Correspondence analysis (Legendre and Legendre, 1998) was 
performed for the separate ordination of the 113 sites $\times 240$ species abundance table $(\mathrm{L})$. The application of correspondence analysis allows RLQ analysis to maximize the covariance between linear combinations of environmental variables and biological traits (Dolédec et al., 1996). This maximized covariance, projected on orthogonal axes of decreasing contribution to the total value, is called co-inertia.

The comparison of this eigenvalues decomposition (RLQ) with the eigenvalues decomposition from the separate ordinations of the environmental variables $(\mathrm{R})$ and biological traits $(\mathrm{Q})$ tables can show what part of the variance of the original data sets is represented in their common structure. The optimal correlation between sites and species scores from the separate ordination of the species abundance table (L) can be compared with the equivalent correlation from the RLQ analysis, in order to illustrate how well the original species abundance patterns are represented by the associations between environmental variables and biological traits. These associations can be best demonstrated by projecting environmental variables and biological traits side-by-side on the same dimensions of the common co-inertia space.

All analyses were performed using the statistical software $\mathrm{R}$ version 3.2.2 (R Core Team, 2015) with the package ade4 (Dray and Dufour, 2007).

\section{S.1.2 Results}

The eigenvalues decomposition of the RLQ analysis shows that the proportion of the common structure between environmental variables and biological traits that is portrayed along the first axis (73\%) is much larger than the proportion that is portrayed along the second one (17\%). The first two axes combined represent $90 \%$ of the covariance between environmental variables and biological traits. The cumulated amount of variance that is preserved on the first two axes of the RLQ ordination, compared to the equivalent variance from the separate ordinations of the environmental variables (R) and biological traits $(\mathrm{Q})$ tables, is just over $85 \%$ in both cases. The correlation values between sites and species scores along the first and second axes of the RLQ analysis are $76 \%$ and $60 \%$ of the respective correlation values from the separate ordination of the species abundance table (L).

The side-by-side projection of environmental variables (Fig. S1a) and biological traits (Fig. S1b) on the first two dimensions of the common co-inertia space reveals one conspicuous pattern: coarse sediment types are strongly associated with trait values that represent preference for gravel or rock (T6), no role in sediment engineering (T14), an 
epifaunal position (T9) and the role of basibionts (T13). These trait values, along with the one that identifies epibiotic organisms (T13) and is associated with increasing water depth, are all characteristic of benthos that occupies the surface of the seabed, supported by structure of abiotic or biotic origin. Increasing water depth is further associated with a transition from organisms that tolerate tidal exposure to those that have to be submerged in high salinity levels (T5).

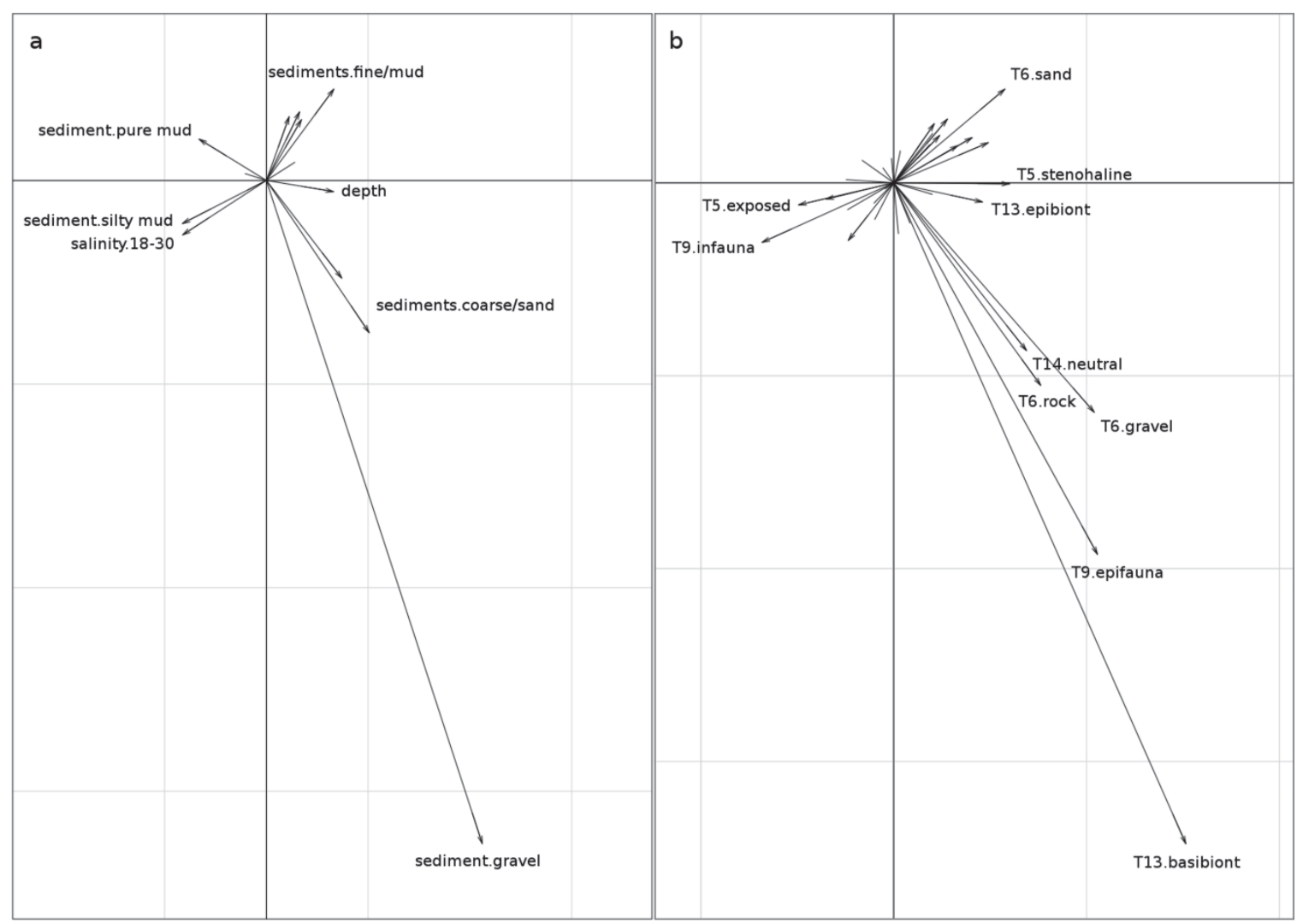

Fig. S1 Projection of a) environmental variables and b) biological traits on the first two dimensions of the common co-inertia space of the RLQ analysis. In both graphs the horizontal axis represents the first dimension and the vertical the second. In the case of continuous and ordinal variables, the arrows indicate the direction of increasing values. In the case of nominal and binary variables, the tips of the arrows indicate the position of the centroids for the respective variable values (shown as variable.value). Plural in the variable names indicates the representation of multiple values that are close in nature and ordination. For details about the traits, see Table 2 


\section{S.2 Functional trade-offs}

\section{S.2.1 Methods}

Our set of 14 biological traits allows the representation of functional trade-offs through specific combinations of trait values. In the case of a trade-off among benthic macroinvertebrates in their utilization efficiency for the two basic resources (food and space) (Tilman, 1980), we would expect trait values that confer a competitive advantage for each resource (greater size (T7) and lower minimum space requirement (T8)) to be negatively associated. A trade-off in the allocation of resources toward early survival versus colonization potential (Tilman, 1990) would result in the survival-enhancing brooded early development mode (T2) being negatively associated with both dispersal distance (T3) and maximum fecundity (T4). Finally, the stabilizers of the mobility-mode hypothesis (Posey, 1987) are expected to bind fine particles, thus leading to the creation of muddy sediments, while destabilizers are expected to disrupt the substrate, resulting in more heterogeneous sediment types. Since each group is assumed to create sediment conditions that are favourable to its own members and detrimental to those of the opposite group, sediment preferences (T6) among stabilizers and destabilizers should correspond to their respective effects on the substrate (T14).

Because values were assigned to the species independently for each biological trait, we can assess the ecological pertinence of each hypothesis, by inspecting the biological traits data set, looking for the respective trait associations. The multivariate ordination technique of Hill and Smith allowed the transformation of the 240 species $\times 14$ biological traits table into a set of orthogonal variables that contain decreasing portions of the table's total variance (Hill and Smith, 1976). The eigenvalues decomposition, on which this technique is based, reveals the amount of variance that each of these variables represents. The projection of the initial trait variables on the first few axes of the transformed multivariate space can provide insights into the most important associations among biological traits.

All analyses were performed using the statistical software $\mathrm{R}$ version 3.2.2 ( $\mathrm{R}$ Core Team, 2015) with the package ade4 (Dray and Dufour, 2007).

\section{S.2.2 Results}

The eigenvalues decomposition of Hill and Smith for the biological traits data set shows that about twice as much variation can be found along each of the first two axes $(15 \%$ and $14 \%$ of total variation) compared to each of the two axes that follow ( $8 \%$ and $7 \%$ of total 
variation). The first four axes combined represent just over $43 \%$ of the total variation of biological traits among species of benthic macroinvertebrates.

The projection of biological traits on the first four dimensions of the transformed multivariate space reveals the most important biological trait associations. Along the first axis (Fig. S2a), maximum size (T7) is assumed to define a competitive hierarchy for food. Minimum space requirement (T8), in the same direction of the axis, is expected to define an inverse competitive hierarchy for space.

On the positive half of the first axis (Fig. S2a), high levels of maximum fecundity (T4) and dispersal distance (T3) are associated with planktonic early development mode (T2). The combination of these trait values is expected to lead to higher colonization potential among marine benthos. On the negative half of the same axis, low levels of maximum fecundity (T4) and dispersal distance (T3) are associated with brooded early development mode (T2) and high population growth rate (T11), thus forming a trait combination that is assumed to enhance early survival rates.

The second axis of the Hill and Smith ordination (Fig. S2a) mainly serves to distinguish organisms with an epifaunal position (T9) and requirement for hard substrates (T6). Trait differences among the rest of the organisms, which are mostly associated with soft bottoms (T6), are featured along the first (Fig. S2a) together with the third and fourth axes of the ordination (Fig. S2b). It appears that sessile organisms (T10) that prefer mud (T6), stabilize the sediment (T14) and create substrate for epibionts (T13) are distinguished from mobile (T10), destabilizing organisms (T14) that have a preference for coarser and mixed sediment types (T6). 


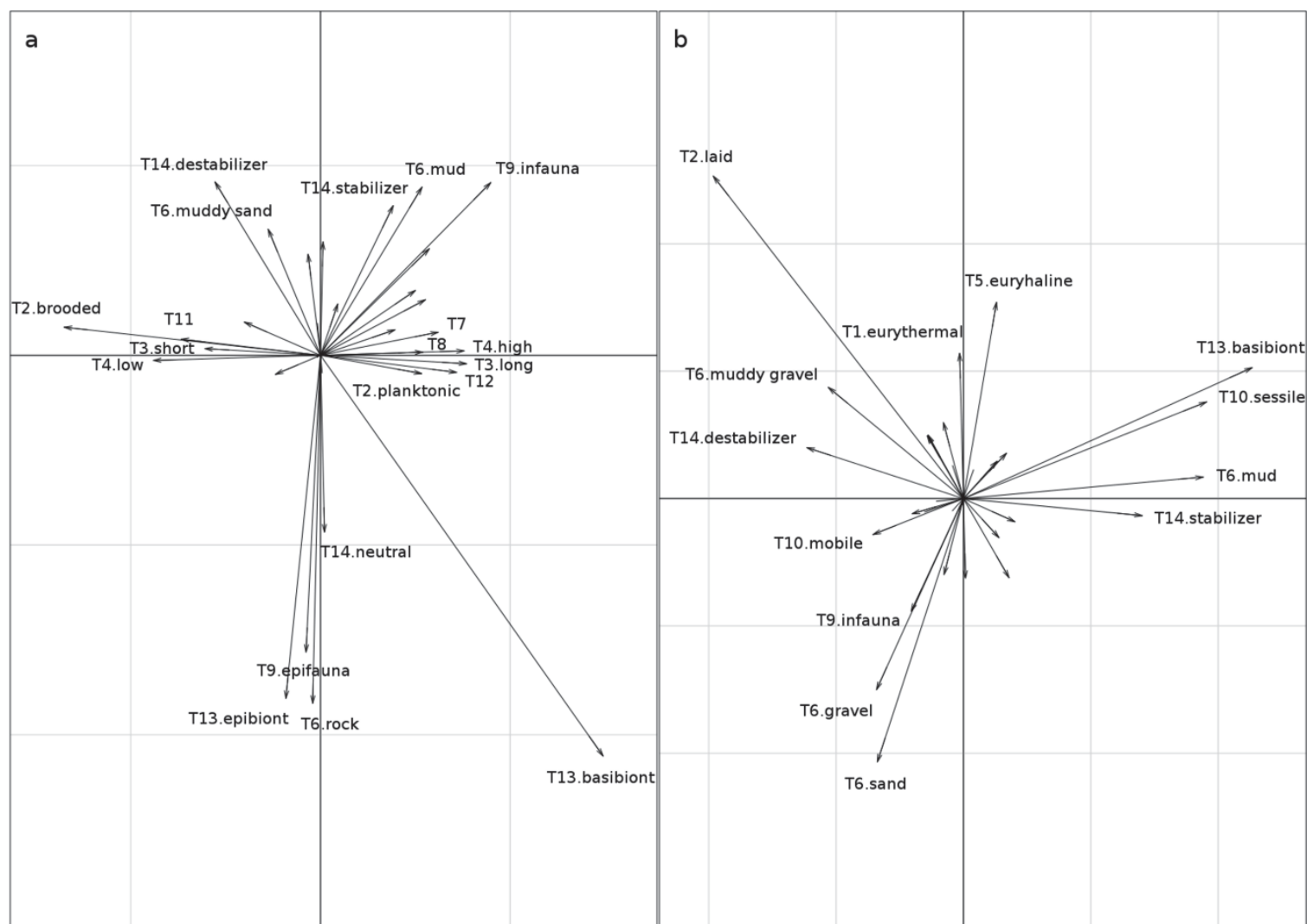

Fig. S2 Projection of biological traits on a) the first and second and b) the third and fourth dimensions of the transformed multivariate space of Hill and Smith analysis. In both graphs the horizontal axis represents the lower dimension and the vertical the higher. In the case of continuous and ordinal traits, the arrows indicate the direction of increasing values. In the case of nominal and binary traits, the tips of the arrows indicate the position of the centroids for the respective trait values (shown as trait.value). For details about the traits, see Table 2 


\section{References}

Bonnot-Courtois, C., 1997. Evolution de la répartition des sédiments dans l'estuaire de la Rance, 1883-1994. Atlas Permanent de la Mer et du Littoral 3, 29.

Desroy, N., 1998. Les peuplements benthiques de substrats meubles du bassin maritime de la Rance. Évolution de la biodiversité et effets de l'activité prédatrice de Nephtys hombergii (Annélide Polychète). PhD Thesis. Université de Rennes 1, Rennes, France.

Dolédec, S., Chessel, D., Ter Braak, C.J.F., Champely, S., 1996. Matching species traits to environmental variables: a new three-table ordination method. Environ. Ecol. Stat. 3, 143-166.

Dray, S., Dufour, A.B., 2007. The ade4 package: implementing the duality diagram for ecologists. J. Stat. Softw. 22, 1-20.

Hill, M.O., Smith, A.J.E., 1976. Principal component analysis of taxonomic data with multistate discrete characters. Taxon 25, 249-255.

Legendre, P., Legendre, L., 1998. Numerical ecology. Second English edition. Elsevier, Amsterdam, Netherlands.

Posey, M.H., 1987. Influence of relative mobilities on the composition of bentic communities. Mar. Ecol.-Prog. Ser. 39, 99-104.

R Core Team, 2015. R: a language and environment for statistical computing. R Foundation for Statistical Computing, Vienna, Austria.

Tilman, D., 1980. Resources: a graphical-mechanistic approach to competition and predation. Am. Nat. 116, 362-393.

Tilman, D., 1990. Constraints and tradeoffs: toward a predictive theory of competition and succession. Oikos 58, 3-15. 